\title{
Emotion emphasis effects in moral judgment are moderated by mindsets
}

\author{
Johannes T. Doerflinger ${ }^{1,3,4}$ (1) Peter M. Gollwitzer ${ }^{2,3}$
}

Published online: 18 July 2020

(c) The Author(s) 2020

\begin{abstract}
In two studies, emotion emphasis effects on moral judgment are demonstrated. The studies indicate that emphasizing negative consequences in trolley-type dilemmas with emotional language produces more utilitarian responses if such emphasis is on the consequences of the deontological option, and more deontological responses if it is on the consequences of the utilitarian option. This effect was moderated by action-phase related mindsets. Individuals in an implemental mindset were less susceptible to the emotion emphasis effect than individuals in a deliberative mindset (Studies 1,2). By also using an eyetracking task in Study 2, we demonstrated that our implemental mindset participants' visual attention was more focused-in particular on goal-directed means-than that of the deliberative mindset participants.
\end{abstract}

Keywords Mindset theory of action phases $\cdot$ Trolley-type dilemmas $\cdot$ Moral judgment $\cdot$ Emotion emphasis

In 2005, the German government created the Aviation Security Act as a response to the $9 / 11$ terrorist attacks. The Act would have allowed the military to shoot down commercial airplanes if they had been hijacked by terrorists to be used as weapons. The Federal Constitutional Court argued that it was unlawful to sacrifice innocent lives even to save others, and that human lives cannot be weighed in numbers. Thus, the act was annulled (Spendel 2006). This case qualifies as a moral dilemma where a utilitarian option (i.e., an option for which the preference is primarily determined by the expected outcome) is in conflict with the deontological ethics (i.e., a priori rules). ${ }^{1}$

Electronic supplementary material The online version of this article (https://doi.org/10.1007/s11031-020-09847-1) contains supplementary material, which is available to authorized users.

Johannes T. Doerflinger

johannes.doerflinger@uni-konstanz.de

1 German Cancer Research Center, 69120 Heidelberg, Germany

2 Department of Psychology, New York University, New York, NY 10003, USA

3 Present Address: Department of Psychology, University of Konstanz, P.O. Box 39, 78457 Constance, Germany

4 Graduate School of Decision Sciences, University of Konstanz, 78457 Constance, Germany
Typically, many variables affect people's moral judgments (Christensen et al. 2014) in cases such as the Aviation Security Act. For instance, the tone of language used to describe a moral dilemma can influence people's responses (Borg et al. 2006). If the dilemma above were presented with dramatic emphasis on the horrifying death of the passengers in the airplane, the response is likely to be different from the response to a neutral presentation. Indeed, past research (Bartels 2008) has shown that vivid descriptions (i.e., an emotional emphasis) of moral dilemmas tend to produce more deontological judgments than neutral descriptions. This finding has been linked to an aversive affective response to the utilitarian option, which is in line with models of moral judgment where deontological judgments are

\footnotetext{
${ }^{1}$ In the present paper, we are using the terms utilitarian and deontological to denote the two behavioral responses (i.e., moral judgments) that are given as options in the dilemmas. This is in line with the conventional use of these terms in the experimental literature on trolleytype dilemmas. In the broader philosophical sense (Mill 1861/2006), utilitarianism refers to a class of normative theories in which it is assumed that one ought to maximize the greater good from an impartial perspective (Rom and Conway 2018), whereas deontology refers to a class of normative theories assuming that some actions are in and of themselves morally right or wrong (Davis 1993). Note that we do neither claim that individuals choosing the utilitarian or deontological option (in the narrower sense of the respective behavioral response) are committed to these moral philosophies nor that the cognitive processes underlying moral judgment in our experiments necessarily line up with utilitarian or deontological thinking in the philosophical sense.
} 
understood as primarily a product of emotional processes and utilitarian judgments are understood as primarily a product of analytic reasoning (Greene et al. 2004; Moore et al. 2011; Shenhav and Greene 2014). However, as pointed out by Bartels (2008), it is likely that a more nuanced picture of moral judgment will emerge if theorists do not just consider how emotionally upsetting a moral dilemma is, but also which specific aspects (e.g., consequences for the individual or the larger group) of the moral dilemma are upsetting to the person making a moral judgment.

Therefore, we focus on manipulating the target of emotional emphasis in moral dilemmas. We argue that emotionally expressive language can shift moral judgments both towards utilitarianism and deontology. If the circumstances surrounding the Aviation Security Act were presented with emphasis on the consequences for the potential victims of a terrorist attack, moral judgments of the case are likely to be skewed in the direction of utilitarian responses. And if the case was presented with an emphasis on the situation of potential victims in the airplane, moral judgments can be expected to be more in favor of the deontological option.

Moreover, it is plausible to assume that emotional emphasis does not affect decision makers in all situations equally. Our aim in the present article is to demonstrate whether and how the impact of emotional emphasis depends on one's mode of information processing. We focus here on the deliberative and implemental mindsets as outlined in the Mindset Theory of Action Phases, because differences in attention and processing of information between these two mindsets should affect how receptive individuals are to information emphasized by emotional language (MAP, Gollwitzer 1990, 2012; Gollwitzer and Keller 2016).

\section{The role of emotional responses in trolley-type dilemmas}

The case of the German Aviation Security Act bears many similarities to the trolley problem, a prototypical moral dilemma that has been discussed in both the psychological and philosophical literatures (Foot 1983; Thomson 1985; Heinzelmann et al. 2012). The standard version of the trolley problem is a hypothetical moral dilemma in which a runaway trolley is approaching a group of five people on the track. If the protagonist does not interfere, the trolley will hit and kill the group of five people. The only way to avoid the death of these people is to sacrifice the life of a single person. One can construct similar scenarios with the same structure, and we will refer to this class of dilemmas as trolley-type dilemmas. In trolley-type dilemmas the protagonist must choose between two options: a utilitarian option, typically sacrificing the life of one person or a small group in order to save a larger group, and a deontological option, typically refraining from killing a person or small group of people.

\section{Dual process models of moral judgment}

There is converging evidence that emotional responses support the formation of deontological judgments. Individuals presented with personal moral dilemmas, a class of dilemmas that evoke strong negative emotions, make consistently more deontological judgments than individuals presented with impersonal, less emotional dilemmas (Greene 2009; Greene et al. 2001; Hauser et al. 2007; McDonald et al. 2017; Moore et al. 2011). Moreover, individual differences in emotional processing including empathic concern predict deontological vs. utilitarian judgments (e.g., Conway and Gawronski 2013); stronger deontological inclinations are found for people who are high in emotional processing. Evidence for the causal role of emotions in moral dilemma judgment is provided by studies where the affective response is manipulated. Downregulating the emotional response to harmful actions (Lee and Gino 2015) or externally inducing positive affect with a different task to counteract the emotional alarm response in moral judgments (Cushman et al. 2012) leads to more utilitarian judgments in personal moral dilemmas (Valdesolo and DeSteno 2006).

Taken together, these findings support dual process accounts (Greene et al. 2001) according to which judgments of trolley-type dilemmas consist of an analytical evaluation of the outcomes favoring the utilitarian option and an emotional reaction favoring the deontological option, which are then integrated into an overall moral judgment (see Shenhav and Greene 2014).

\section{Outcome aversion predicts moral judgments}

Deontological judgments represent the rejection of causing harm. Accordingly, the emotional component in trolley-type judgments has been described as an empathic aversion to personally harming others (Crockett et al. 2010). Miller et al. (2014) questioned whether this is in fact mainly an empathic reaction to victims suffering, or a reaction to the harmful actions themselves. They distinguished two types of emotional concerns involved in harm rejection: action aversion (i.e., a negative emotional response to performing harmful actions) and outcome aversion (i.e., a negative emotional response to witnessing harm). They found that action aversion but not outcome aversion consistently predicted moral dilemma judgments.

Reynolds and Conway (2018) have used process dissociation methods to extract parameters for deontological and utilitarian inclinations as two independent processes driving overall moral judgments. They observed that outcome aversion but not action aversion is positively related to both 
deontological and utilitarian inclinations. When these inclinations jointly contribute to overall moral judgments, the effects of outcome aversion canceled each other out. These results suggest that emotional concerns related to the outcome of decisions can increase both a utilitarian and a deontological preference. We thus specifically focus on emotional emphasis related to outcomes. Emphasizing either the harm resulting from the deontological option or the harm resulting from the utilitarian option can be expected to increase an aversion to the respective outcomes. This should shift overall moral judgments in favor of the utilitarian and deontological option in the respective conditions.

\section{Emotion emphasis in moral judgments}

When investigating the impact of emotional processes on moral judgment it is important to consider that emotions are directed at a target (Colman 2008). Being upset about the consequences of the utilitarian option in a moral dilemma (which is a common response to personal moral dilemmas; Greene et al. 2001) will increase deontological inclinations. Similarly, negate affect can also be directed at the consequences of the utilitarian option driving deontological inclinations. In both cases outcome aversion would be driving the emotional response (Reynolds and Conway 2018), but these emotional responses can be expected to affect moral judgments differently.

We propose that emotion-based outcome aversion can be manipulated by adding emphasis to the consequences of either the deontological or the utilitarian option in trolley type dilemmas, without drastically altering the content of the dilemmas. We refer to this manipulation as emotion emphasis. Emotion emphasis is manipulated by the use of affectladen language with an emotional rephrasing of dilemma content. This emphasis should increase the saliency of and create negative affect associated with the respective options.

Although there is suggestive evidence for the impact of using emotionally expressive language on moral judgments (e.g., Nichols and Knobe 2007), some studies have only found modest effects (Borg et al. 2006). This may be because the linguistic style is a very subtle manipulation of emotional framing. An additional puzzle piece may pertain to the nature of emotions. Emotions are, in contrast to moods, by definition evaluative and directed at an object (Colman 2008). Consequently, we argue that there is no strong link between emotional expressive language per se and deontological preferences. Rather, we propose that how emotional expressive language influences moral judgments depends on what the emotions are directed at. We hypothesize:

H1 Emotionally expressive language can both increase and decrease the preference for utilitarian judgments depending on the target of the emotion. If negative outcomes of the utilitarian option are emphasized, then respondents should demonstrate a relatively stronger preference for the deontological option, and if negative outcomes of the deontological option are emphasized, then respondents should demonstrate a relatively stronger preference for the utilitarian option.

\section{Mindsets}

According to the Mindset Theory of Action Phases (MAP, Gollwitzer 1990, 2012; Gollwitzer and Keller 2016; Heckhausen and Gollwitzer 1987), individuals process information differently, depending on their current stage of goal pursuit. Such differences in information processing are likely to influence how we react to factual information and emotion emphasis in moral dilemmas. In MAP, goal pursuit is subdivided into four consecutive phases. In each phase, the agent deals with a specific challenge of goal pursuit and thus develops a phase-specific mindset that promotes successfully overcoming the challenges at hand. In the present studies, we focus on the mindsets that are active in the first two phases: the deliberative mindset and the implemental mindset. We chose those mindsets because the deliberative mindset is characterized by open-mindedness to new information, a wide breadth of attention, and preferential encoding and retrieval of outcome related information. In contrast, the implemental mindset is characterized by closed-mindedness, narrow breadth of attention, and cognitive tuning in favor of goal implementation (Gollwitzer and Bayer 1999). These characteristics can be expected to moderate the effects of emotion emphasis. Both these features of the deliberative mindset should lead to a greater impact of emotion emphasis on moral judgments. A wider breadth of attention and openminded processing should result in individuals considering overall more information (including emotion emphasis). In addition, tuning toward outcome information facilitates processing of emotion emphasis, when this emphasis is aimed at the potential outcomes of a scenario.

\section{Information processing and breadth of attention}

In past research, mindset effects have been demonstrated to affect the breadth of attention (summary by Gollwitzer 2012). For instance, in a series of studies Fujita et al. (2007) first induced deliberative vs. implemental mindsets and then had the participants work on a mental concentration task. During some trials of the task, task-irrelevant words were incidentally displayed. The authors assessed how accurately the participants remembered the incidentally presented irrelevant stimuli in a recognition memory task. Participants who were in a deliberative mindset had significantly better recognition rates for the irrelevant information than participants in an implemental mindset. Additionally, response latencies 
in the recognition task were faster for participants in the deliberative mindset as compared to the implemental mindset. In sum, the Fujita et al. studies show that openness to incidental information is higher in the deliberative than in the implemental mindset.

To demonstrate that mindsets affect attention, Büttner et al. (2014) conducted three experiments in which they measured the breadth of visual attention after a mindset induction. They found that participants in a deliberative mindset perceived lines in an adapted Müller-Lyer optical illusion task as longer, compared to participants in an implemental mindset (Studies 1,2) — an effect that indicates a wider breadth of attention (Predebon 2004). Furthermore, the authors demonstrated in an eye-tracking task that participants in a deliberative mindset explored nature scenes presented in photographs more evenly, whereas participants in an implemental mindset spent more time looking at depicted foreground objects (Study 3).

Taken together, these studies provide evidence for the open-minded processing of information and broad distribution of attention in the deliberative mindset, and a closedminded processing of information and narrow distribution of attention in the implemental mindset.

\section{Tuning towards outcome versus implementation relevant information}

The primary function of the deliberative mindset is finding an end to the pre-decisional action phase by committing to a goal. Broad attention to all the available information and open-minded processing should aid the selection of goals that one wants to pursue. Moreover, outcome related information is especially important, because optimal goal selection requires the agent to realistically assess the desirability and feasibility of goal candidates (Gollwitzer and Keller 2016). Therefore, individuals in the deliberative mindset have been theorized to preferentially process outcome related information compared to individuals in the implemental mindset (Gollwitzer 1990, 2012; Gollwitzer and Bayer 1999). After individuals have committed to a goal, outcome information is no longer relevant, as the task in the post-decisional action phase is goal implementation. Accordingly, in the implemental mindset cognitive tuning is geared towards the processing of implementation-relevant information (i.e., means for action initiation).

Gollwitzer et al. (1990, Study 2) have tested these assumptions. To induce a deliberative vs. implemental mindset, participants were asked to choose between different test materials. Either before (deliberative mindset condition) or after the participants made their decision (implemental mindset), they were presented with information about a third party (e.g., an elderly lady) thinking about a decisional problem (e.g., "Should I invite my grandchildren to stay at my house over the summer—or shouldn't I?"), possible outcomes (e.g., "It would be good, because they could help me keep up my garden."), and implementational steps involved in the potential course of action (e.g., "If I decide yes, then I won't talk to the kids before my daughter has agreed."). After a short distractor task, the participants were asked to recall the information about the decision problems presented to them earlier. Participants in the implemental mindset recalled more thoughts about goal implementation, while participants in the deliberative mindset recalled more thoughts about the potential outcomes.

Because in the present studies emotion emphasis targets the outcome of the dilemmas, this emphasis should be preferentially processed in the deliberative mindset compared to the implemental mindset. Therefore, we hypothesize that the features of these two mindsets should moderate emotion emphasis effects.

$\mathrm{H} 2$ We expect individuals in a deliberative mindset to be more prone to emotion emphasis effects, and individuals in an implemental mindset to be less affected by them.

\section{Testing mindset induced attention effects with moral dilemmas}

Furthermore, investigating moral dilemmas also provides us with the opportunity to test how specific the attention effects in deliberative vs. implemental mindsets are. Büttner et al. (2014) have shown that individuals in an implemental mindset have a narrower focus of attention than individuals in a deliberative mindset. In their study, they could not show what specific content individuals in an implemental mindset focus their attention on, as the stimuli used did not have narrative content. However, visual depictions of trolley type dilemmas can be used to serve this purpose, as trolley type dilemmas can be constructed to have a standardized narrative structure with the same elements (two groups of potential victims, means for taking action, and background environment). Mindset theory predicts that individuals in an implemental mindset should be concerned with initiating goal-directed actions. Thus, they should be cognitively tuned to attend to the depicted means. In other words, pictures showing the situation of trolley type dilemmas where a decision is to be made are suited to test this prediction.

H3 Individuals in an implemental mindset will specifically attend more to means for taking action than individuals in a deliberative mindset. 


\section{Present research}

The aim of the present experiments is to test whether emotion emphasis effects are moderated by the currently active action-phase related mindset. In particular, we investigate the influence of the deliberative and implemental mindsets (Gollwitzer 1990, 2012; Gollwitzer and Keller 2016). These mindsets have been shown to affect the breadth of attentional focus and information processing. Emotion emphasis that targets the potential outcomes of moral dilemmas should have a stronger effect for on individuals in the deliberative mindset, for the following reasons: First, processing in the deliberative mindset is characterized by broad, open-minded processing, which makes it generally more likely that available information (including emotion emphasis) influences decision making, whereas the implemental mindset is characterized by narrow, closed-minded processing. Second, cognitive tuning is geared towards outcome-related information in the deliberative mindset, and towards implementation-related information in the implemental mindset.

A set of scenarios was created as stimuli for the present studies that met the criteria of a trolley-type dilemma. The scenarios are based on the materials used by Greene et al. (2004) and Moore et al. (2008) as well as additional dilemmas created for the purpose of this study. For each dilemma, a neutral version, a version with emphasis on the harmful consequences in case of taking the utilitarian option (harmful-utilitarian version, $H U$ ), and a version with emphasis on the harmful consequences in case of taking the deontological option (harmful-deontological version, $H D$ ) were created. All core information about the dilemmas was provided in the neutral version. For HU and HD versions, a short paragraph was added that provided emotional information about the dilemma.

For the standard trolley dilemma, this results in the following variants of the dilemma.

[All variants] You are at the wheel of a runaway trolley quickly approaching a fork in the tracks. On the tracks extending to the left is a group of five railway workers. On the tracks extending to the right is a single railway worker. If you do nothing, the trolley will proceed to the left, causing the deaths of the five workers.

[HD variant] In that case these five workers would see the approaching trolley unable to flee from their dire situation before being hit by the trolley. They would die an agonizing death.

[All variants] The only way to avoid the deaths of these workers is to hit a switch on your dashboard that will cause the trolley to proceed to the right, causing the death of the single worker.

[HU variant] In that case the single worker would see the approaching trolley unable to flee from his dire

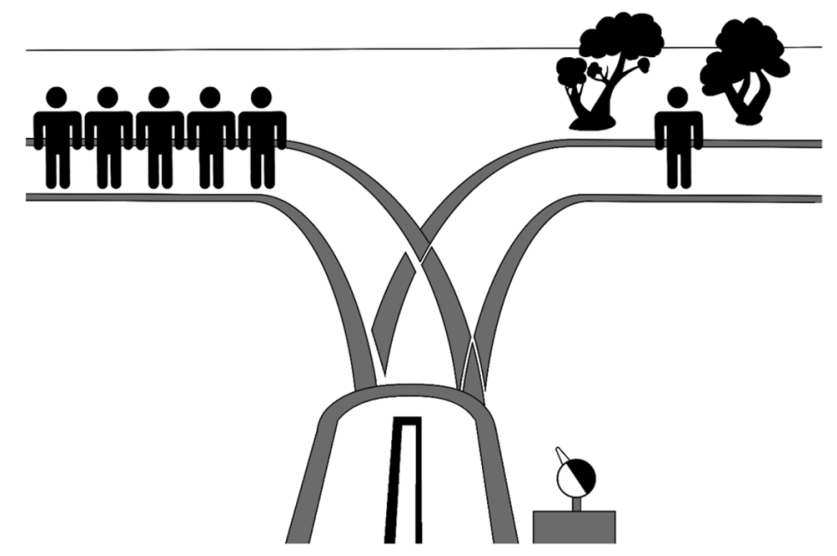

Fig. 1 Example of a picture used for the moral dilemma task in Study 2. Trees were added to balance the visual saliency of the single individual on the right side and the group on the left

situation before being hit by the trolley. He would die an agonizing death.

Eight moral dilemmas with this structure were created for Study 1 . The dilemmas and mean endorsement of utilitarianism for each dilemma can be found in the supplemental materials. Note that for most dilemmas the average judgments were slightly in favor of the utilitarian option. This is to be expected, since the dilemmas where constructed based on impersonal dilemmas for which this pattern is typical (Greene et al. 2004). For Study 2 the dilemmas were refined, and additional items were added. In Study 2 , pictures representing the dilemmas were used in addition to written text. See Fig. 1 for an example of such a picture. The dilemmas and their corresponding pictures are included in the supplemental materials.

The studies reported in the present work were conducted in accordance with the ethical principles of the APA. The studies were reviewed and approved by the Board of the Graduate School of Decision Sciences at the University of Konstanz, Germany. The raw decision data for all three experiments are available on the Open Science Framework: https://osf.io/kbvjp/?view_only=b94b90f1a5 9a449cb71b1fd2253e9cd0.

We calculated mixed models for hypothesis testing to account for the fact that each participant rated multiple dilemmas. Given this data structure, mixed models provide a powerful and robust approach (Boisgontier and Cheval 2016). Mixed models were computed for both studies with the lme4 package for R (Bates et al. 2015). For mixed linear models, test statistics were approximated using the Satterthwaite approximations for degrees of freedom in the lmerTest package for R (Kuznetsova et al. 2017). In all mixed models, random intercepts for participants and trials were included. 


\section{Study 1: mindsets as moderators of emotion emphasis effects}

Study 1 was designed to demonstrate emotion emphasis effects on moral judgment. Furthermore, we explored the moderating effect of the deliberative vs. implemental mindset (Gollwitzer 1990, 2012; Gollwitzer and Keller 2016) on emotion emphasis effects. We predicted that an implemental mindset reduces emotion emphasis effects, whereas a deliberative mindset enhances them.

\section{Method}

\section{Participants and design}

The experiment had a 3 (Emotion Emphasis: HU vs. no emphasis vs. HD) $\times 3$ (Mindset: deliberative vs. control vs. implemental) between participants design and was conducted as an online experiment on the platform prolific.ac (Palan and Schitter 2018). Assuming that mindset effects are small to medium-sized and responses to different trolleytype dilemmas are moderately correlated, a power analysis with $G^{*}$ Power was conducted (Faul et al. 2007). To achieve a statistical power of $1-\beta=0.95,288$ participants would be needed. We recruited 306 participants. Only participants who had not taken part in earlier moral dilemma studies from our lab, and who also had a general acceptance rate higher than $90 \%$ for prior studies on prolific. ac, were admitted. This second restriction was put in place to ensure that task involvement was high. The participants were paid 2 British Pounds. One participant entered seemingly random letters in the mindset induction task, another participant failed an attention check, and a third participant indicated in a debriefing question that it was hard to take the study seriously. These three participants were excluded from the data analysis. Consequently, our sample size amounted to 303 ( 125 female, 171 male, 7 other/did not indicate) with a mean age of 26.5 ( $S D=9.4$, age range: 16 to 52 ).

\section{Procedure}

Mindsets were induced with a standard procedure used in mindset studies (Gollwitzer and Keller 2016). To create a deliberative mindset, participants were instructed to think of a complex personal problem they had not yet decided to act upon and elaborate positive and negative long- and short-term consequences of taking action. After deliberating about the consequences of taking action, participants were asked to repeat this process by thinking about the consequences of not taking action. To induce an implemental mindset, participants were asked to think about a complex personal project on which they had already decided to act upon but had not started yet and name five steps necessary to complete the project. In addition, they were asked to indicate when, where, and how they would act on each of these steps. Examples of problems/projects suitable for the mindset task were: changing your field of study, moving out of an apartment, or getting to know someone new. In the control condition, participants were asked to indicate the times of their main meals for each day (i.e., breakfast, lunch, and dinner) in the last week.

\section{Manipulation check}

Participants in the two mindset conditions were asked to mark on a visual analogue scale representing a timeline where they saw themselves in relation to the problem/project they worked on during the mindset task. The scale had "making a decision" at its center. Participants in the deliberative mindset condition were expected to place their mark on the left side of making the decision (before making a decision), and participants in the implemental mindset condition were expected to place their mark on the right side of making the decision (after making a decision). The scale was coded ranging from 1 on the left side to 100 on the right side.

\section{Moral dilemma task}

After the mindset induction, the participants worked on the moral dilemma task. Each participant was asked to rate eight trolley-type dilemmas. Emotion Emphasis was manipulated by showing participants only the dilemma version corresponding to their respective experimental condition (HU vs. no emphasis vs. HD). The dilemmas were presented in random order. The participants were instructed to rate the moral wrongness of the utilitarian option (e.g., "It is morally wrong to hit the switch.") on a 5-point scale ranging from "I strongly disagree" to "I strongly agree".

After providing moral judgments for each dilemma, the dilemmas were again presented in randomized order and the participants were asked to indicate on 5-point scales ranging from "I strongly disagree" to "I strongly agree" how emotional they thought the dilemmas were ("The story was very emotional.") and how difficult it was to make a moral judgment ("Making a decision for this dilemma was very difficult.").

At the end of the experiment, demographic variables were assessed. Among these demographic questions an attention check was interspersed. This question was a multiple-choice question in a drop-down format, which could be answered: "left," "right," "bottom," and "top." The participants were instructed on the same page to select the option "bottom." 
Table 1 Mixed linear model estimating moral judgments in Study 1

\begin{tabular}{|c|c|c|c|c|c|}
\hline Variable & $B$ & $S E B$ & $d f$ & $t$ & $p$ \\
\hline Intercept & 3.04 & 0.19 & 8.85 & 16.28 & $<.001$ \\
\hline Mindset $^{\mathrm{a}}$ & -0.04 & 0.06 & 302.13 & -0.65 & .519 \\
\hline Emphasis $^{\text {b }}$ & 0.12 & 0.06 & 302.13 & 2.21 & .028 \\
\hline Mindset $^{\mathrm{a}} \times$ emphasis $^{\mathrm{b}}$ & 0.12 & 0.06 & 302.13 & 1.87 & .063 \\
\hline \multirow[t]{2}{*}{ Random effects $\left(s^{2}\right)$} & Participant & & Trial & & \\
\hline & 0.72 & & 0.51 & & \\
\hline
\end{tabular}

${ }^{\mathrm{a}}$ Implemental $=-1$, control $=0$, deliberative $=1$

${ }^{\mathrm{b}} \mathrm{HU}=-1$, no emphasis $=0, \mathrm{HD}=1$

Finally, the participants were asked to indicate what they thought the purpose of the present study was.

\section{Results}

\section{Manipulation checks}

Participants in the deliberative mindset condition indicated on average that they saw themselves as predecisional on the timeline $(M=45.93, S D=22.8)$, whereas participants in the implemental mindset condition indicated that they saw themselves as postdecisional on the timeline $(M=58.1$, $S D=22.3$ ). An independent samples $t$-test revealed that this difference was significant, $t(202.54)=3.83, p<0.001$.

A mixed linear model with the emotionality ratings for each dilemma as the criterion and the emphasis condition as predictor revealed that both HU dilemmas $(M=3.69$, $S D=1.25), t(300.02)=2.89, p=0.004$, and HD dilemmas $(M=3.55, S D=1.31), t(300.02)=1.98, p=0.049$, were rated as more emotional than the no emotion emphasis dilemmas $(M=3.27, \mathrm{SD}=1.39)$. Emotionality ratings for the $\mathrm{HD}$ and HU dilemmas did not differ from each other significantly, $t(302.53)=1.05, p=0.295$, and the difficulty ratings did not differ between conditions, $t \mathrm{~s}<1.32, p \mathrm{~s}>0.18$.

\section{Moral judgments}

The experimental condition variables and their interaction were entered as predictors in a linear mixed model with the moral judgments for each dilemma as the criterion. The main effect of Mindset was not significant, $t(299.00)=-0.64$, $p=0.522$, whereas Emotion Emphasis had a significant main effect on moral judgments, $t(299.00)=2.20, p=0.029$. This main effect was qualified by a marginally significant interaction of Mindset and Emotion Emphasis, $t(299.00)=1.86$, $p=0.065$. For more information on the model see Table 1 . The mean moral dilemma ratings are visualized in Fig. 2.

To test whether the observed effect was indeed due to different effects of emphasis in the two manipulated mindsets, we conducted a follow-up analysis focusing on the mindset (deliberative vs. implemental) and emphasis conditions (HU vs. HD) as a robustness check. We observed a significant interaction of mindset and emphasis, $t(162.01)=1.99$, $p=0.049$ (see the full model in the supplementary materials).

Planned contrast tests specific to $H 2$ revealed that participants in the deliberative mindset condition endorsed the utilitarian option significantly more often in the HD condition than in the HU condition, $t(301.01)=2.48, p=0.014$. A similar trend was observed for the no-mindset control condition, $t(301.00)=1.66, p=0.098$. Moral judgments of participants

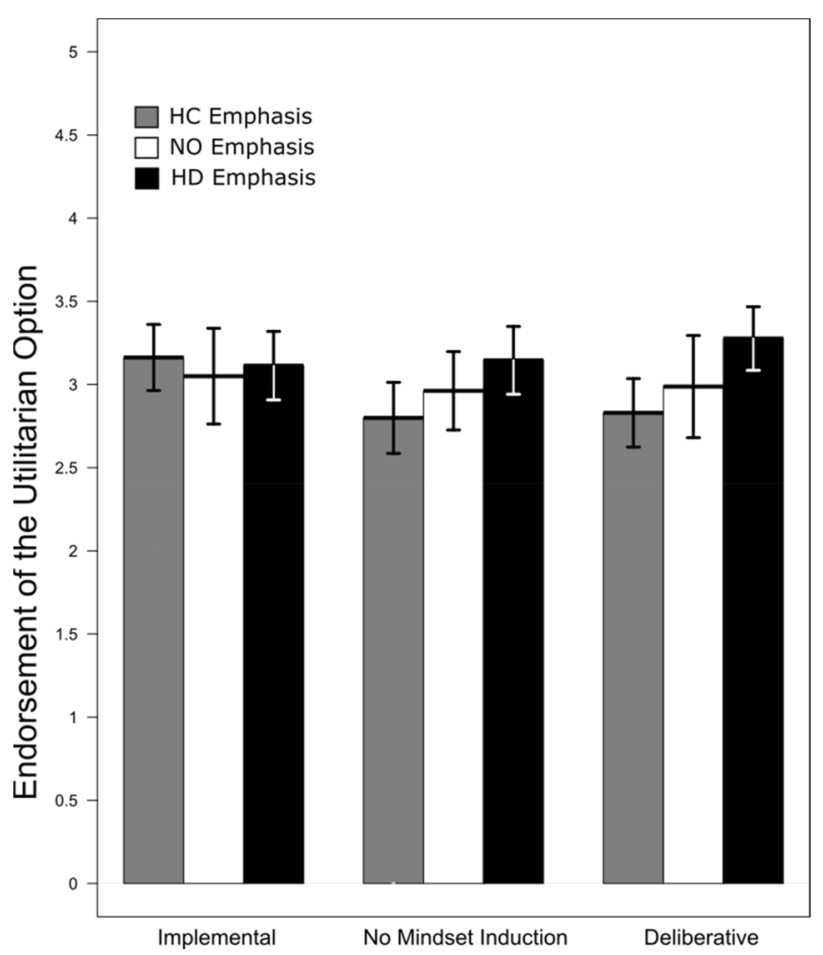

Fig. 2 Mean endorsement of the utilitarian options by experimental conditions in Study 1, error bars represent 95\% confidence interval 
in the implemental mindset condition did not differ between emotion emphasis conditions, $t(301.00)=0.19, p=0.847$.

\section{Discussion}

In Study 1, we observed an emotion emphasis effect. In line with H1, participants endorsed the utilitarian option more in dilemmas where the emotion emphasis was geared against deontological judgments (i.e., in the HD dilemmas), and they endorsed the deontological option more in dilemmas where the emotion emphasis was geared against utilitarian judgments (i.e., in the HU dilemmas). This finding underscores that the use of expressive language can influence moral judgments. Our study goes beyond previous work by using verbal emphasis to target the specific alternatives in trolley-type dilemmas. We attached an emotional tag to either the deontological or the utilitarian option, targeting the outcomes of the respective options. Our study moreover suggests that the effects of expressive language go beyond a simple one-to-one mapping of emotion and deontology. How emotion emphasis affected people's moral judgments apparently depended on what content was emphasized. That is, emotion-driven processes stemming from an emphasis of the negative consequences of the deontological option also increased utilitarian judgments.

Importantly, emotion emphasis effects were moderated by the induced mindsets. As can be seen in Fig. 2, the emotion emphasis conditions differed for participants in a deliberative but not an implemental mindset, with the control participants showing a pattern similar to the deliberative mindset participants. Thus, the occurrence of emotion emphasis effects was affected by the prevalent mindset in line with $\mathbf{H 2}$.

The planned contrast comparing the emphasis conditions in the no-mindset control condition did not reach significance. In line with the proposed theoretical framework, emphasis effects were more pronounced for participants in the deliberative mindset and less pronounced for participants in the neutral control mindset. The interaction effect including the no-mindset and no-emphasis conditions was only marginally significant (although a significant contrast testing the hypothesized pattern was observed). A robustness check analyzing the 2 (Mindset: deliberative vs. implemental) by 2 (Emphasis: HU vs. HD) interaction revealed a significant result. Still, replication is called for. Ideally, such a replication study should also target the underlying cognitive mechanisms. We propose that emphasis effects are eliminated in the implemental mindset because attention in the implemental mindset is focused on implementation-relevant content. This narrowing of focus should diminish the effects of added emotional information that targets the outcome. In contrast, undirected attention and open-minded information processing in the deliberative mindset should increase the influence of such emotion emphasis on moral judgment. Study 2 was designed to (a) replicate the moderating effect of mindsets on emotion emphasis effects on moral judgments, and (b) assess attentional focus associated with the two mindsets investigated in the present work.

\section{Study 2: replication and an exploration of visual attention in different mindsets}

In Study 2, we aim to conceptually replicate the interaction of mindsets and emotion emphasis and to further explore the role of mindsets on attention. To show that mindsets can carry over from a completely unrelated activity, in Study 2 a new method to induce mindsets was used. Participants were given short monologues from Shakespeare's play Hamlet in which the protagonist was either deliberating about a choice he has not yet made, or laying out a plan to achieve a goal he was committed to. The participants were instructed to identify themselves with the protagonist and relive his thoughts.

On the side of the dependent variables, a major addition in Study 2 is that we measured visual attention while participants looked at schematic images depicting the scenario in the trolley-type dilemmas. Deliberative and implemental mindsets have been shown to affect attention differently (Büttner et al. 2014; Fujita et al. 2007). In a deliberative mindset, attention is relatively open-minded whereas an implemental mindset is closed-minded. In the present Study 2 , we go one step further. We propose that attention in an implemental mindset (relative to a deliberative mindset) is not just more focused in general, but also more focused specifically on goal-directed means.

Büttner et al. (2014) assessed mindset effects on attentional breadth using an eye-tracking task. The authors first established a deliberative vs. implemental mindset and then instructed the participants to evaluate pictures of nature scenes. This study points to overall differences in narrow vs. broad focus of attention between the mindsets investigated. However, because the scenes used as stimuli depicted only static objects without narrative content (i.e., nature scenes), the Büttner et al. study does not yet answer the question of whether attention in the implemental mindset is focused more on goal-directed means and action-relevant content than the deliberative mindset.

The systematic structure of trolley-type dilemmas qualifies them as a suitable task paradigm to test whether attention in the implemental mindset is indeed focused more on goal-directed means than in the deliberative mindset. Trolley-type dilemmas can be constructed such that each dilemma has a goal-directed means that can be visualized (e.g., a button or a lever). The means of the potential action represents content that is important for the implementation (action vs. inaction) of the critical response. Consequently, 
we expect individuals in an implemental mindset to focus more on these elements, compared to individuals in a deliberative mindset when they look at a visual depiction of a trolley-type dilemma they have to resolve. This should result in more fixations on means in the implemental mindset condition as compared to the deliberative mindset condition.

In sum, then, the present Study 2 has two aims: First, it serves as a conceptual replication of the Emphasis by Mindset interaction effect observed in Study 1. Second, we aim to show that attention in an implemental mindset is more focused on content that is related to action implementation as compared to a deliberative mindset.

\section{Method}

\section{Participants and design}

The experiment had a 2 (Emotion Emphasis: HU vs. HD) $\times 2$ (Mindset: deliberative vs. implemental) between participants design. The design was reduced to the relevant conditions to save resources due to the more demanding setup including eye-tracking. Ten dilemmas were created. Using a more controlled laboratory setting for conducting Study 2, we aimed at a power of $1-\beta=0.80$. A power analysis with $\mathrm{G}^{*}$ Power (Faul et al. 2007) resulted in a target sample size of 100 participants. We recruited 108 participants ( 93 female, mean age $22, S D=4.08$, age range $16-41$ ) at a German university. The participants received 7 Euros or course credit as compensation for taking part in the study.

\section{Procedure}

The study was advertised as an experiment about literature interpretation and moral judgment. Up to four participants took part in each session. The participants were placed into individual cubicles and randomly assigned to experimental conditions. The experimenter was blind to conditions, and all tasks and instructions were computerized.

\section{Mindset manipulation}

All participants were told that the first task was to interpret a monologue from the play Hamlet. They received a short description of the plot of the play, the scene in which their assigned monologue was featured, and a summary of the content of the monologue. Participants in the deliberative mindset were asked to work on a monologue from the first scene of the third act of the play ("To be or not to be"). A central characteristic of the monologue is that Hamlet is indecisive and has not made up his mind - features of the predecisional phase which is associated with a deliberative mindset. The monologue ends before he reaches a decision.
Participants in the implemental mindset condition received a soliloquy from Act 2 , Scene 2 ("The play's the thing"). In the soliloquy, Hamlet lays out the steps of a plan and it ends with his strong determination to act-features of the postdecisional phase which is associated with an implemental mindset.

The participants in both mindset conditions were asked to analyze the texts by taking Hamlet's perspective and to imagine what he would be thinking and feeling. Guiding questions based on standard mindset manipulations were provided to the participants. After completing the literature task, the participants were asked to indicate on a visual analogue scale-representing a timeline with making a decision at its center-where they thought Hamlet was in relation to making a decision. This comprehension check parallels the manipulation check in the standard mindset task. We also assessed how difficult the participants thought it was to take Hamlet's perspective ("It was easy for me to take Hamlet's perspective.", German: "Es fiel mir leicht, mich in Hamlet hineinzuversetzen.") on a six-point rating scale ranging from "I agree" to "I disagree." We did this because we were concerned that the mindset by emphasis interaction effect might be weaker for participants who had difficulties with the task.

\section{Materials and technical setup}

After the mindset induction task, the participants resolved ten trolley-type dilemmas. The stories were partly based on materials used in Study 1, but additional dilemmas were added to increase the number of trials. The dilemmas in Study 2 all had the features of trolley-type dilemmas and were created with two emphasis variants. All of the selected dilemmas were such that they could be visualized in schematic pictures. In the pictures we presented the means for the utilitarian action (e.g., a lever), the people who would be harmed in case the utilitarian option was chosen, and the people who would be harmed in case the deontological option was chosen. Additional background (e.g., railways) was added to create a coherent scene. Ten dilemmas and corresponding pictures were created that closely met these requirements (see Fig. 1 for an example of a picture depicting the standard trolley case). The dilemmas and the respective pictures are included in the supplemental material.

The moral judgment task was implemented in PsychoPy (Peirce 2007). The task made use of eye-tracking to assess gaze data during picture presentation, and participants controlled the task by looking at answer keys. Stimuli were presented on a 19-inch monitor with a screen resolution of $1280 \times 1024$ pixels. Eye-tracking data were collected using a Gazepoint GP3 eye tracker with a sampling rate of $60 \mathrm{~Hz}$. The eye tracker was placed at the bottom of the screen and participants sat approx. $70 \mathrm{~cm}$ from the screen; the eye tracker was approx. $50 \mathrm{~cm}$ below the participants' eye-level. 
Fig. 3 Sequence of screens in each trial of Study 2

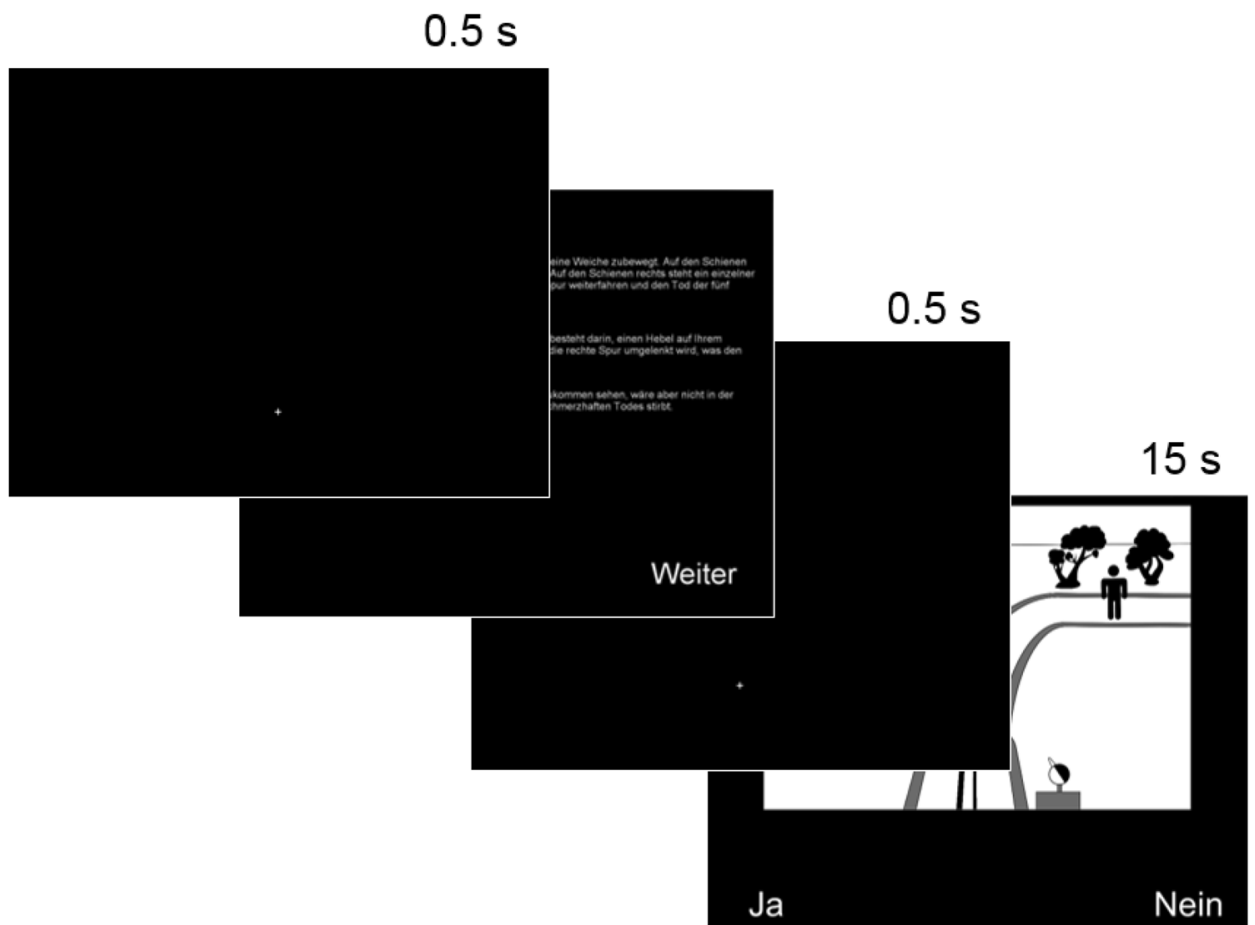

To minimize head movements, chin rests were provided. The eye tracker was connected to the experimental software with the iohub event monitoring framework for PsychoPy.

\section{Moral judgment task}

At the beginning of the task, the participants received headphones and then the chinrests were adjusted. Headphones were needed later on because the experiment included an auditory signal. The eye-trackers were calibrated with the Gazepoint Control software. Next, the moral judgment task was explained to the participants and the participants were familiarized with the task procedure. They were asked to take the moral dilemmas seriously even if they might seem unrealistic. The moral dilemma texts were presented with an emotion emphasis manipulation that was identical to the manipulation in Study 1. The participants were instructed to first read each of the moral dilemmas carefully. At the end of each dilemma the question "Is it morally wrong to [perform the utilitarian action]?" had to be answered. Next, a fixation cross was shown in the lower section of the screen for $500 \mathrm{~ms}$. Then, a picture representing the respective moral dilemma was presented. The participants were instructed to look at the picture for at least $15 \mathrm{~s}$. A sound notified the participants when this time had elapsed. After $15 \mathrm{~s}$, the participants could indicate their moral judgments by looking at the words "Yes" or "No" in the lower corners of the screen. We adopted a categorical Yes vs. No response format to allow the task to be performed complete in the eye tracking setup. This was done to keep the participants' attention on the screen. We did not expect the response format to affect the processes of interest. Figure 3 depicts the sequence of events in a given trial.

The position of responses (right corner vs. left corner) and the orientation of the pictures (original vs. mirror image) were counterbalanced between participants. The eye-trackers were recalibrated after five trials. Moral judgment responses and gaze data during the picture presentation served as dependent variables. Each picture showed a means to perform an action (e.g., a lever), a small group of people (or a single person), and a larger group of people. AOIs were defined with an approx. 50-pixel border around these objects. After completing the moral judgment task, the participants provided demographic information, were thanked, paid, and thoroughly debriefed.

\section{Results}

\section{Comprehension check and perceived task difficulty}

The participants in the deliberative mindset condition rated the protagonist in the literature task as more predecisional $(M=40.45, S D=13.59)$ than the participants in the implemental mindset condition $(M=59.31, S D=22.36)$, $t(89.66)=7.63, p<0.001$. Perceived difficulty of the literature task did not differ significantly between the mindset conditions, $t(105.42)=-0.43, p=0.667$. However, a linear regression revealed a significant interaction effect of perceived difficulty and mindset condition on the comprehension check variable, $F(1,103)=4.04, p=0.047$, indicating 
that participants who had difficulties with the task tended to rate the monologues in the opposite direction (i.e., participants who had difficulties systematically misunderstood the task). Thus, we decided to include perceived task difficulty as a moderator in our main analysis.

\section{Moral judgments}

To test the combined effects of mindset and emotion emphasis on moral judgments, a mixed linear logit model was computed with the moral judgment decisions as the criterion, and emphasis, mindset, and perceived difficulty in the mindset task, as well as the interaction terms as predictors. Random intercepts were estimated for each participant and each moral dilemma. There were significant main effects of Emotion Emphasis $(z=-2.10, p=0.036)$, Mindset $(z=-2.01, p=0.044)$, and task difficulty $(z=-2.27$, $p=0.023)$. In addition, the interaction effect of Emotion Emphasis and task difficulty $(z=2.20, p=0.028)$ was significant. Importantly, the interaction effect of Mindset and Emotion Emphasis was also significant $(z=2.18, p=0.029)$. As in Study 1, this interaction effect indicates a more pronounced influence of emotion emphasis for participants in the deliberative mindset condition compared to the implemental mindset condition (see Fig. 5). Moreover, the interaction effect was qualified by a significant three-way interaction of Mindset, Emotion Emphasis, and task-difficulty $(z=-1.97, p=0.048)$ suggesting that the Mindset by Emotion Emphasis moderation effect of interest was strongest for those participants who had no difficulties with the mindsetinduction task, and weaker for those participants who had difficulties with the task. For more detail on the model see Table 2. The mindset by emphasis interaction effect holds up in a model that does not include the task difficulty, given that only those participants who passed the comprehension check and indicated no severe difficulties with the task are included ( $\mathrm{n}=92), z=2.13, p=0.033$.

\section{Gaze data}

The eye-tracking data were prepared for analysis using the eyetrackingR (Dink and Ferguson 2015) and the saccades (von der Malsburg 2015) packages for R. Data from two participants were discarded because of low data quality (high amount of track loss). We calculated fixations during the passive picture presentation phase for each trial with the built-in function of the saccades package. Figure 5 shows the distribution and density of fixations for each dilemma presented, separate for the deliberative and the implemental mindset condition. Two-dimensional kernel density is an indicator for the clustering of data points in a two-dimensional space. In the case of fixations, higher density signifies that the gaze was more concentrated and fixations were closer to each other, thus serving as an indicator of focus. As can be seen in Fig. 5, the maximum density averaged over trials is higher in the implemental mindset $\left(M=6.397 \times 10^{-6}, S D=0.874 \times 10^{-6}\right)$ than in the deliberative mindset $\left(M=4.803 \times 10^{-6}, S D=1.541 \times 10^{-6}\right)$ condition.

A mixed linear logit model over all fixations was computed to test whether the higher fixation density in the implemental mindset was a result of focusing on a particular area of interest (i.e., the means). In the model, the independent variables (i.e., mindset and emphasis) and their interaction served as predictors, and random intercepts were included for participants and trials. Mindset-task difficulty had no effect on fixations, $z \mathrm{~s}<0.98, p s>0.323$, and thus this control variable was not included in the model. For a summary, see Table 2. In the model the main effect of Mindset was significant, $z=-2.04, p=0.042$, indicating a higher proportion of fixations on the means for participants in the implemental mindset condition $(M=0.14)$ than for participants in the deliberative mindset condition $(M=0.12)$. In separate analyses where we tested fixations on the sets of victims, no significant effects of experimental conditions were found, $z \mathrm{~s}<0.68, p \mathrm{~s}>0.49$.

\section{Discussion}

As can be seen in Fig. 4, the emphasis effect was moderated by the currently active mindset. While participants in the deliberative mindset condition chose in line with the emotion emphasis manipulation, this effect was absent for participants in the implemental mindset condition. Controlling for the influence of perceived mindset induction task difficulty, the results of Study 2 qualify as a conceptual replication of the main findings of Study 1, and further suggest that action-phase related mindsets are an effective regulating mechanism for emotion emphasis effects. This qualifies as additional support for $\mathbf{H 2}$.

The central pattern of results was more pronounced for participants who had no difficulties with the mindset task. Participants who had difficulties with the mindset task seem to have systematically misunderstood the task as indicated by the comprehension check. Therefore, perceived difficulty affected the participants' responses. Future studies using a similar manipulation should ensure that it is not too difficult for the targeted sample.

In line with the mindset theory of action phases (Gollwitzer 1990, 2012; Gollwitzer and Keller 2016), we had predicted that selective attention in an implemental mindset is directed more at goal-relevant means than in a deliberative mindset $(\mathbf{H 3})$. Our eye-tracking data support this hypothesis. As can be seen in Fig. 5, the overall density of fixations is higher in the implemental mindset condition 
Table 2 Mixed linear logit models estimating moral judgments and attentional focus on means in Study 2

\begin{tabular}{|c|c|c|c|c|}
\hline Variable & $B$ & $S E B$ & $z$ & $p$ \\
\hline \multicolumn{5}{|l|}{ (a) Moral judgments } \\
\hline Intercept & 2.42 & 0.76 & 3.20 & .001 \\
\hline Mindset $^{\mathrm{a}}$ & -2.11 & 1.05 & -2.02 & .044 \\
\hline Emphasis $^{\mathrm{b}}$ & -2.08 & 0.99 & -2.10 & .036 \\
\hline Difficulty & -0.45 & 0.20 & 2.27 & .044 \\
\hline Mindset $^{\mathrm{a}} \times$ emphasis $^{\mathrm{b}}$ & 3.27 & 1.50 & 2.18 & .029 \\
\hline Difficulty $\times$ emphasis $^{\mathrm{b}}$ & 0.59 & 0.27 & 2.20 & .028 \\
\hline Mindset ${ }^{\mathrm{a}} \times$ difficulty & 0.52 & 0.29 & 1.82 & .069 \\
\hline Mindset $^{\mathrm{a}} \times$ emphasis $^{\mathrm{b}} \times$ difficulty & -0.80 & 0.41 & -1.97 & $=.048$ \\
\hline \multicolumn{5}{|c|}{ (b) Proportion of fixations on the means } \\
\hline Intercept & -2.16 & 0.30 & -7.17 & $<.001$ \\
\hline Mindset $^{\mathrm{a}}$ & -0.24 & 0.12 & -2.04 & .042 \\
\hline Emphasis ${ }^{\mathrm{b}}$ & -0.04 & 0.11 & -0.38 & .705 \\
\hline Mindset $^{\mathrm{a}} \times$ emphasis $^{\mathrm{b}}$ & 0.17 & 0.16 & 1.07 & .285 \\
\hline Random effects $\left(s^{2}\right)$ & \multicolumn{2}{|l|}{ Participant } & \multicolumn{2}{|l|}{ Trial } \\
\hline Moral judgments & \multicolumn{2}{|l|}{1.26} & \multicolumn{2}{|l|}{0.48} \\
\hline Fixations on means & \multicolumn{2}{|l|}{0.02} & \multicolumn{2}{|l|}{0.84} \\
\hline
\end{tabular}

${ }^{\text {a }}$ Deliberative $=1$, implemental $=-1$

${ }^{\mathrm{b}} \mathrm{HU}=-1, \mathrm{HD}=1$

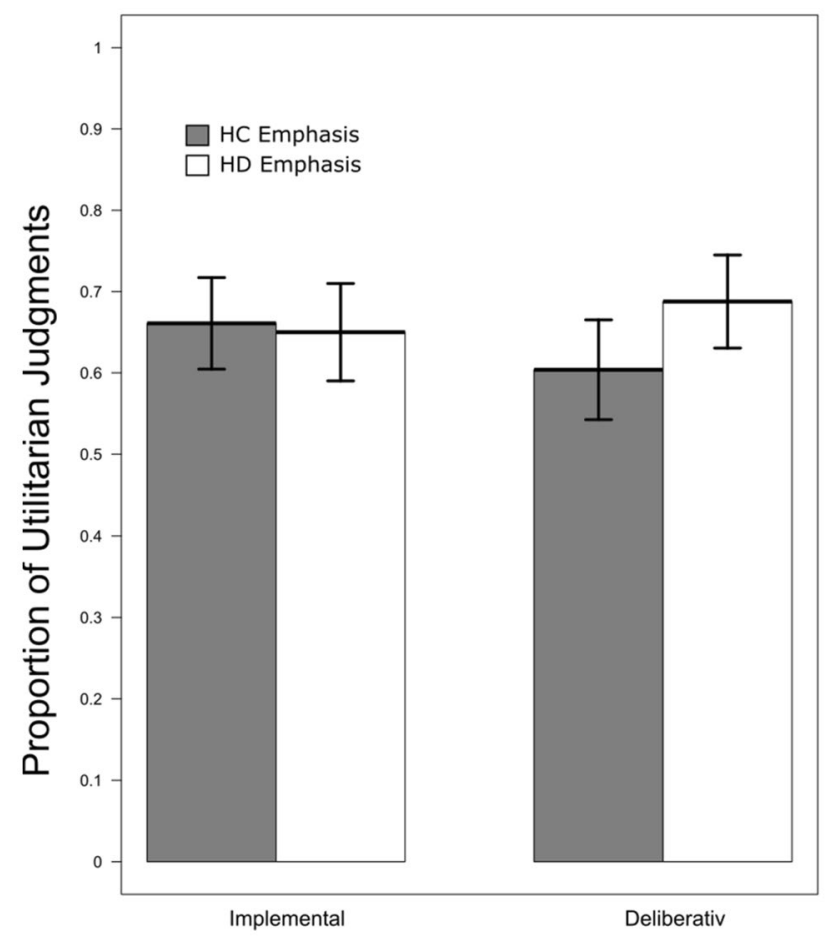

Fig. 4 Proportion of endorsement of the utilitarian options by experimental conditions in Study 2, error bars represent 95\% confidence interval than in the deliberative mindset condition. This indicates that the fixations in the deliberative mindset were more broadly distributed over the entire screen, while fixations in the implemental mindset were more focused on particular areas. These findings line up with Büttner et al. (2014) who have shown that visual attention is narrower in the implemental mindset than in the deliberative mindset. Importantly, however, we went one step further and tested what individuals in an implemental mindset focused on while looking at a scene with goal-relevant, meaningful content. As expected, the proportion of fixations on means for actions was indeed higher for participants in the implemental mindset.

Our study used a novel method for inducing deliberative vs. implemental mindsets. This showcases that action-phase related mindsets can be activated by procedural priming (Fujita and Trope 2014). In other words, the cognitive procedures constituting the deliberative and the implemental mindset can be activated by having participants engage in activities that demand the execution of these procedures, but also having participant observe a protagonist who engages in one or the other type of reasoning. We used Hamlet as the protagonist as he has been referred to as only the "prince of Denmark", but the "king of deliberation" (Armor and Taylor 2003). 

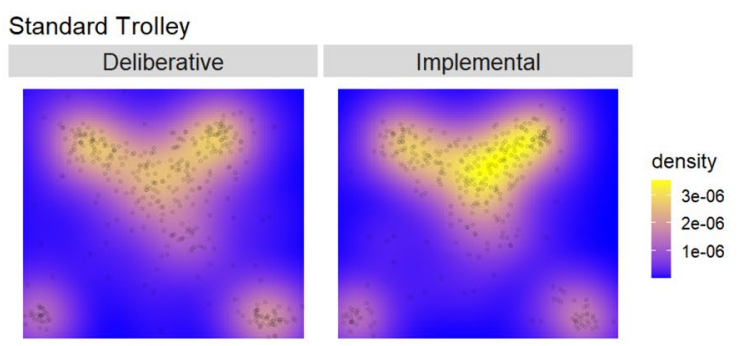

Airplane Hijacking
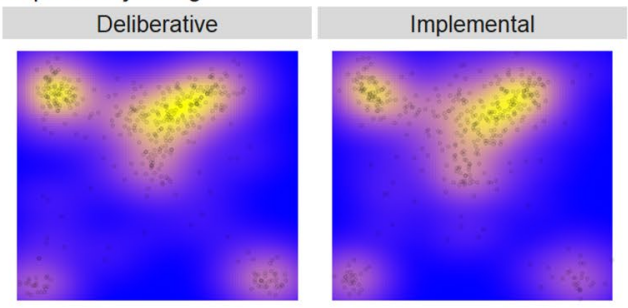

density

$4 \mathrm{e}-06$
$3 \mathrm{e}-06$

$3 \mathrm{e}-06$
$2 \mathrm{e}-06$

$-1 \mathrm{e}-06$
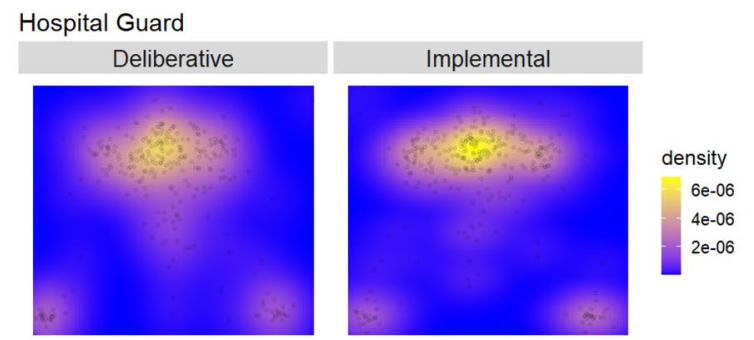

Mine Shaft

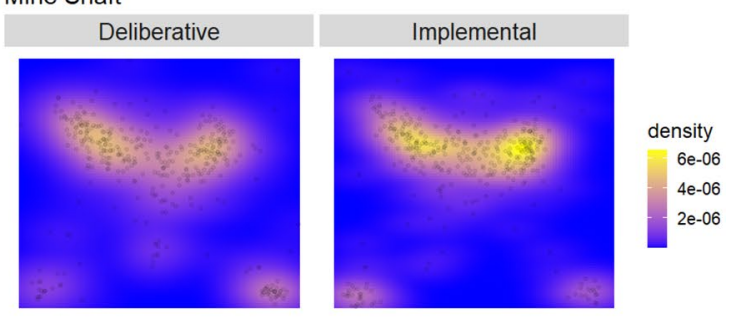

\section{Motorway}
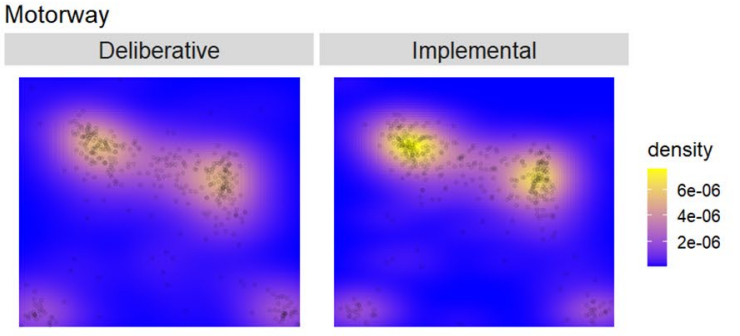

Wild Water

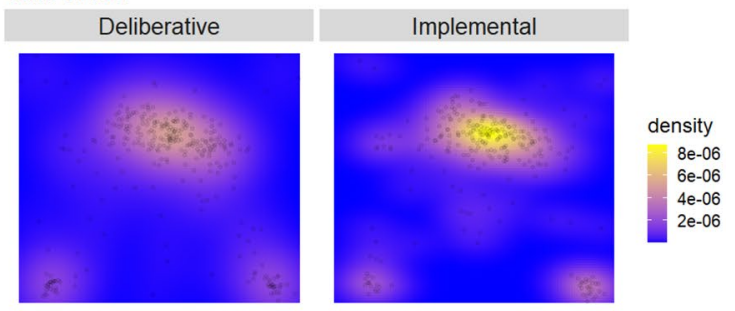

\section{Coast Guard}
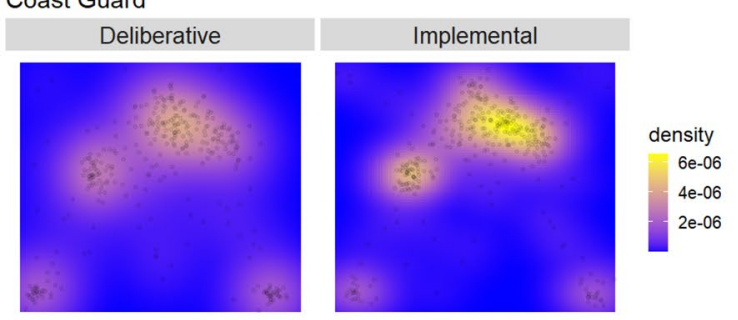

Cave Rescue

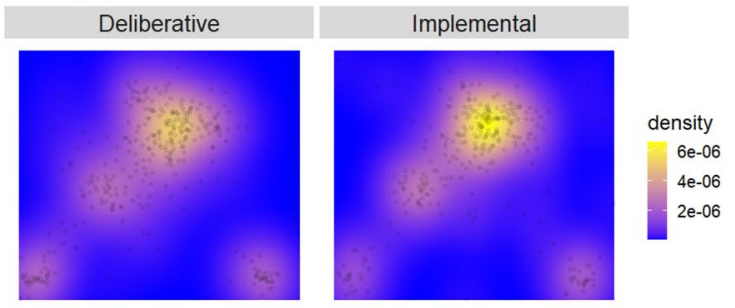

Office Fire
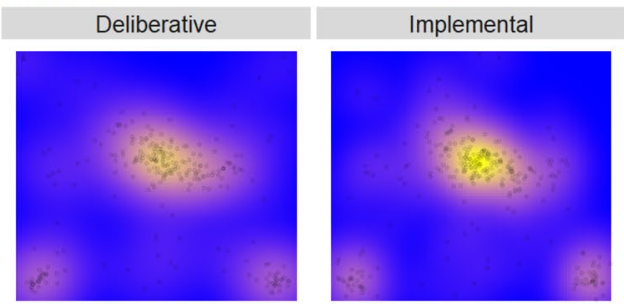

\section{Biking Accident}

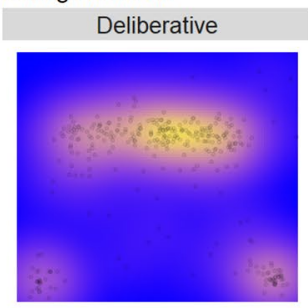

Implemental

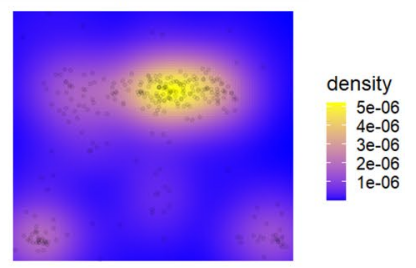

Fig. 5 Distribution and density of fixations for each dilemma separated by mindset conditions in Study 2. Dots represent individual fixations; colors indicate the density of fixations 


\section{General Discussion}

We demonstrated in two studies that emotionally emphasizing the negative consequences in trolley-type dilemmas can affect moral judgments to be both more utilitarian when the negative consequences of a deontological choice are emphasized, and to be more deontological when the negative consequences of a utilitarian choice are emphasized. This is an important addition to the existing literature on moral judgment and emotions (e.g. Greene 2010,), because it highlights that emotional responses are directed at an object. Researchers should therefore take the target of emotion emphasis into account when more precise predictions of moral judgments are desired. Furthermore, the present studies suggest that emotional processes can in fact also make individuals more utilitarian. These results line up with previous research demonstrating that individuals expend more resources for identified victims than unidentified statistical victims (i.e., the identifiable victim effect; Jenni and Loewenstein 1997), an effect that is in part driven by comparatively stronger emotional concerns for identified victims (Erlandsson et al. 2015).

Our data revealed that emotion emphasis effects were affected by the action-phase related mindsets we had induced. Being placed into a deliberative mindset coincides with a widening of attention and breadth of information processing, which opens the agent up to influences by information including emotional emphasis. A deliberative mindset is adaptive when the agent needs to process as much information as possible to make an informed decision (Gollwitzer 2012; Gollwitzer and Keller 2016). However, once a goal is set, an implemental mindset is needed that shields actors from processing information that could derail goal striving. Such shielding apparently is powerful enough to modulate the influence of emotion emphasis in a moral dilemma, thus making people less susceptible to emotion emphasis effects. As action-phase related mindsets alter the selectivity of attention and the breadth of information processing, emotion emphasis effects are increased when attention and information processing are characterized by much breadth (in the deliberative mindset) and decreased when attention and information processing focus on goal implementation (in the implemental mindset).

Implemental mindsets are typically activated when individuals have already reached a goal decision and start to plan out its implementation. Helzer et al. (2017) have shown that individual differences in moral dilemma judgments are relatively stable. Thus, people seem to have a trait-like disposition to favor either utilitarianism or deontology. This default may be altered, however, by situational context variables (e.g., emotional emphasis). Because the deliberative mindset is typically associated with open-minded goal setting, people may be more open to the influences by context factors. In contrast, individuals in an implemental mindset being tuned towards defending their already made decisions should be sealed off from such influences.

In our studies, the emotion emphasis targeted potential outcomes of the options in the presented moral dilemmas. It is worth considering recent work on process dissociation (Conway and Gawronski 2013) when discussing emotion emphasis in moral decisions. Most research on moral dilemmas treats outcome maximization and harm rejection as opposites. Participants must choose between deontological and utilitarian options or rate the morality of selecting one of these options, thereby explicitly or implicitly rejecting the nonchosen option. Conway and Gawronski (2013) argue that deontological and utilitarian inclinations can be two independent psychological mechanisms. To test this, the authors applied a process dissociation framework. The key to process dissociation is that both congruent trials (the two processes predict the same decision) and incongruent trials (the two processes predict different decisions) are assessed. By comparing the responses to congruent and incongruent trials, one can calculate independently the strengths of utilitarian and deontological inclinations. Reynolds and Conway (2018) observed that outcome aversion (i.e., a negative emotional response to observing others' suffering) is positively related to both utilitarian and deontological inclinations. However, the combined effects of these inclinations canceled each other out for overall judgments were the deontological and utilitarian options were treated as opposites. The emotion emphasis effects observed in our studies are consistent with these findings, as they illustrate that outcome aversion can be targeted to support both the deontological and the utilitarian inclinations of decision makers.

Finally, we demonstrated with an eye-tracking study (Study 2) that attention in the deliberative mindset is indeed more broadly distributed, whereas attention in the implemental mindset is more focused. In line with the mindset theory of action phases (Gollwitzer 1990, 2012; Gollwitzer and Keller 2016), attention in the implemental mindset turned out to be focused on goal-directed means. We do not assume that this effect is specific to morality related stimuli. The moral dilemmas used in the present studies are suitable to demonstrate attention effects in moral judgments but the observed effects should be apparent in other contexts as well. Future studies should therefore test the generalizability of the means focus we observed in our second study for the implemental mindset. 


\section{Limitations and future research}

Although we found evidence in two studies supporting the hypothesis that action-phase related mindsets moderate the impact of emotion emphasis on moral judgments, this should be seen as first steps stimulating a systematic investigation of the role that mindsets play in shaping the effect of emotion emphasis on moral judgments. In the future, the robustness of such mindset effects should be tested in pre-registered replication studies.

In our studies, we only investigated the impact of emotion emphasis, not other forms of emphasis. One might argue that the observed emphasis effects are due to saliency rather than the experience of negative emotions. Although we do observe that the emphasis conditions were rated as more emotional than the no-emphasis control condition (Study 1), we cannot exclude the possibility that saliency was a driving mechanism of the observed emphasis effects. Future studies should examine whether non-emotional emphasis (e.g., strength of arguments) would also be affected by the currently active mindset. We do however propose that the emphasis effects in our studies are at least partially driven by negative affect associated with the emphasized outcome. The particular role of saliency and of the various components of emotions (e.g., arousal, valence, complexity) should be systematically investigated in future studies. This would also allow to test the emotional processes behind emphasis effects in more detail.

In the present studies, we investigated the emphasis on the potential outcomes of moral dilemma decisions. One of our arguments explaining why the influence of emotion emphasis was stronger in the deliberative mindset as compared to the implemental mindset is that individuals in the deliberative mindset are more tuned towards processing outcome-related information. Accordingly, a different relation of mindset and emotional emphasis is to be expected if the emphasis is placed on the actions involved in the dilemma options rather than the outcome. Given that the implemental mindset favors a focus on action, one should expect that participants in an implemental mindset should be more affected by emotion emphasis on actions than participants in a deliberative mindset.

\section{Depth of reasoning as an alternative explanation}

One might argue that mindset effects might simply arise because participants in a deliberative or implemental mindset differ in how much they think about the given dilemmas. We explored in a pilot study whether a mere induction of thorough reflective thought also qualifies as an effective method to moderate emotion emphasis. To induce reflective thinking, we used a self-regulatory tool (i.e., implementation intentions) that has been shown to be effective in activating intuitive and reflective thought (e.g., Bieleke et al. 2016; Doerflinger et al. 2017). A description of this pilot study, the dataset, and the analysis files can be found on https://osf. io/4azvs/?view_only=643e749b557f4cefb9829c31705d77 46. Our data suggest that emotion emphasis effects on moral judgments are unaffected by making such judgments in a more reflective vs. spontaneous manner. However, further studies are needed before we conclude that mindset effects are due to qualitative differences in processing rather than mere differences in time and effort individuals expend on the dilemma judgments.

\section{The CNI model of moral judgment}

Gawronski et al. (2017) have recently proposed a model of moral decision making (the CNI model). It depicts trolleytype dilemma judgments as a combination of three variables: sensitivity to consequences (C), sensitivity to moral norms $(\mathrm{N})$, and preference for inaction (I). These parameters are extracted from participants' responses to a set of parallel dilemmas via multinomial modelling. The authors argue that the C-parameter does not necessarily depend on analytic reasoning. In line with this, emotion emphasis targeting the consequences did shift moral judgments in our studies. This influence was stronger for participants in the deliberative mindset. We argued that one of the reasons for the mindset moderation is that individuals in the deliberative mindset are more tuned towards processing outcome related information than participants in the implemental mindset. Future studies should explore whether participants working on Gawronski et al.'s dilemmas have a higher C-parameter if they are in a deliberative mindset compared to an implemental mindset. Additionally, in all dilemmas in the present work, the utilitarian option entails taking action, whereas the deontological option equals inaction. Future research should test whether the I-parameter is affected by action-phase related mindsets.

\section{Conclusion}

The present paper shows that emotional emphasis in moral dilemmas can promote utilitarian as well as deontological preferences. We found initial evidence suggesting that such emphasis effects are moderated by action-phase related mindsets. Emphasis effects were increased in the deliberative mindset and decreased in the implemental mindset. Furthermore, we used moral dilemmas in an eye-tracking study to test a special feature of the deliberative vs. implemental mindset: attention has been proposed to be more broadly distributed in the deliberative mindset, and more focused in the implemental mindset (Büttner et al. 2014). In line with the mindset theory of action phases (Gollwitzer 1990, 2012; Gollwitzer and Keller 2016), in our eye-tracking 
study attention in the implemental mindset was indeed more focused (i.e., on goal-directed means).

Acknowledgements Open Access funding provided by Projekt DEAL. The authors gratefully acknowledge financial support from the Graduate School of Decision Sciences at the University of Konstanz. We thank Lea Doerflinger who created the pictures used as stimulus material in Study 2. We thank Dr. Maik Bieleke and Dr. Lucas Keller who provided insight and expertise. We thank Dr. Katrin Platzer, Prof. Frank Rösl, and Dr. Nora Heinzelmann for useful discussions and support.

\section{Compliance with ethical standards}

Conflict of interest The authors declare that they have no conflict of interest.

Ethical approval All procedures followed were in accordance with the ethical standards of the responsible committee on human experimentation (institutional and national) and with the Helsinki Declaration of 1964 and its later amendments.

Informed consent Informed consent was obtained from all patients for being included in the study.

Open Access This article is licensed under a Creative Commons Attribution 4.0 International License, which permits use, sharing, adaptation, distribution and reproduction in any medium or format, as long as you give appropriate credit to the original author(s) and the source, provide a link to the Creative Commons licence, and indicate if changes were made. The images or other third party material in this article are included in the article's Creative Commons licence, unless indicated otherwise in a credit line to the material. If material is not included in the article's Creative Commons licence and your intended use is not permitted by statutory regulation or exceeds the permitted use, you will need to obtain permission directly from the copyright holder. To view a copy of this licence, visit http://creativecommons.org/licenses/by/4.0/.

\section{References}

Armor, D. A., \& Taylor, S. E. (2003). The effects of mindset on behavior: Self-regulation in deliberative and implemental frames of mind. Personality and Social Psychology Bulletin, 29, 86-95. https://doi.org/10.1177/0146167202238374.

Bartels, D. M. (2008). Principled moral sentiment and the flexibility of moral judgment and decision making. Cognition, 108, 381-417.

Bates, D., Mächler, M., Bolker, B., \& Walker, S. (2015). Fitting linear mixed-effects models using lme4. Journal of Statistical Software, 67, 1-48. https://doi.org/10.18637/jss.v067.i01.

Bieleke, M., Gollwitzer, P. M., Oettingen, G., \& Fischbacher, U. (2016). Social value orientation moderates the effects of intuition versus reflection on responses to unfair ultimatum offers. Journal of Behavioral Decision Making, 30, 569-581. https:// doi.org/10.1002/bdm.1975.

Boisgontier, M. P., \& Cheval, B. (2016). The anova to mixed model transition. Neuroscience \& Biobehavioral Reviews, 68, 10041005. https://doi.org/10.1016/j.neubiorev.2016.05.034.

Büttner, O. B., Wieber, F., Schulz, A. M., Bayer, U. C., Florack, A., \& Gollwitzer, P. M. (2014). Visual attention and goal pursuit: Deliberative and implemental mindsets affect breadth of attention.
Personality and Social Psychology Bulletin, 40, 1248-1259. https ://doi.org/10.1177/0146167214539707.

Christensen, J. F., Flexas, A., Calabrese, M., Gut, N. K., \& Gomila, A. (2014). Moral judgment reloaded: A moral dilemma validation study. Frontiers in Psychology, 5, 607. https://doi.org/10.3389/ fpsyg.2014.00607.

Colman, A. (Ed.). (2008). A dictionary of psychology. Oxford: Oxford University Press.

Conway, P., \& Gawronski, B. (2013). Deontological and utilitarian inclinations in moral decision making: a process dissociation approach. Journal of Personality and Social Psychology, 104, 216-235. https://doi.org/10.1037/a0031021.

Crockett, M. J., Clark, L., Hauser, M. D., \& Robbins, T. W. (2010). Serotonin selectively influences moral judgment and behavior through effects on harm aversion. Proceedings of the National Academy of Sciences, 107, 17433-17438.

Cushman, F., Gray, K., Gaffey, A., \& Mendes, W. B. (2012). Simulating murder: the aversion to harmful action. Emotion, 12, 2-7. https:// doi.org/10.1037/a0025071.

Davis, N. (1993). Contemporary deontology. In P. Singer (Ed.), A Companion to Ethics (pp. 205-218). New Jersey: Wiley.

Dink, J. W., \& Ferguson, B. (2015). eyetrackingR: An R Library for eye-tracking data analysis. Retrieved from https://www.eyetrackin gr.com.

Doerflinger, J. T., Martiny-Huenger, T., \& Gollwitzer, P. M. (2017). Planning to deliberate thoroughly: If-then planned deliberation increases the adjustment of decisions to newly available information. Journal of Experimental Social Psychology, 69, 1-12. https ://doi.org/10.1016/j.jesp.2016.10.006.

Erlandsson, A., Björklund, F., \& Bäckström, M. (2015). Emotional reactions, perceived impact and perceived responsibility mediate the identifiable victim effect, proportion dominance effect and in-group effect respectively. Organizational Behavior and Human Decision Processes, 127, 1-14. https://doi.org/10.1016/j.obhdp .2014.11.003.

Faul, F., Erdfelder, E., Lang, A. G., \& Buchner, A. (2007). G* Power 3: A flexible statistical power analysis program for the social, behavioral, and biomedical sciences. Behavior Research Methods, 39, 175-191.

Foot, P. (1983). Moral realism and moral dilemma. The Journal of Philosophy, 80, 379-398. https://doi.org/10.2307/2026455.

Fujita, K., Gollwitzer, P. M., \& Oettingen, G. (2007). Mindsets and pre-conscious open-mindedness to incidental information. Journal of Experimental Social Psychology, 43, 48-61. https://doi. org/10.1016/j.jesp.2005.12.004.

Fujita, K., \& Trope, Y. (2014). Structured versus unstructured regulation: on procedural mindsets and the mechanisms of priming effects. Social Cognition, 32, 68-87. https://doi.org/10.1521/ soco.2014.32.supp.68.

Gawronski, B., Armstrong, J., Conway, P., Friesdorf, R., \& Hütter, M. (2017). Consequences, norms, and generalized inaction in moral dilemmas: The CNI model of moral decision-making. Journal of Personality and Social Psychology, 113, 343-376. https://doi. org/10.1037/pspa0000086.

Gollwitzer, P. M. (1990). Action phases and mind-sets. In E. T. Higgins \& R. M. Sorrentino (Eds.), Handbook of motivation and cognition: Foundations of social behavior (Vol. 2, pp. 53-92). New York: Guilford.

Gollwitzer, P. M. (2012). Mindset theory of action phases. In P. A. M. Van Lange, A. W. Kruglanski, \& E. T. Higgins (Eds.), Handbook of theories of social psychology (Vol. 1, pp. 526-545). London: Sage.

Gollwitzer, P. M., \& Bayer, U. (1999). Deliberative versus implemental mindsets in the control of action. In S. Chaiken (Ed.), Dualprocess theories in social psychology (pp. 403-422). New York: Guilford. 
Gollwitzer, P. M., Heckhausen, H., \& Steller, B. (1990). Deliberative and implemental mind-sets: Cognitive tuning toward congruous thoughts and information. Journal of personality and social psychology, 59, 1119-1127. https://doi. org/10.1037/0022-3514.59.6.1119.

Gollwitzer, P. M., \& Keller, L. (2016). Mindset theory. In V. ZeiglerHill \& T. K. Shackelford (Eds.), Encyclopedia of personality and individual differences (pp. 1-8). Cham, Switzerland: Springer International.

Greene, J. D. (2009). Dual-process morality and the personal/impersonal distinction: A reply to McGuire, Langdon, Coltheart, and Mackenzie. Journal of Experimental Social Psychology, 45, 581584. https://doi.org/10.1016/j.jesp.2009.01.003.

Greene, J. D. (2010). The secret joke of Kant's soul. In T. Nadelhoffer, E. Nahmias, \& S. Nichols (Eds.), Moral psychology: Historical and contemporary readings (pp. 359-372). New Jersey: Wiley-Blackwell.

Greene, J. D., Nystrom, L. E., Engell, A. D., Darley, J. M., \& Cohen, J. D. (2004). The neural bases of cognitive conflict and control in moral judgment. Neuron, 44, 389-400. https://doi.org/10.1016/j. neuron.2004.09.027.

Greene, J. D., Sommerville, R. B., Nystrom, L. E., Darley, J. M., \& Cohen, J. D. (2001). An fMRI investigation of emotional engagement in moral judgment. Science, 293, 2105-2108. https://doi. org/10.1126/science.1062872.

Hauser, M., Cushman, F., Young, L., Jin, K. X. R., \& Mikhail, J. (2007). A dissociation between moral judgments and justifications. Mind and Language, 22, 1-21. https://doi.org/10.111 1/j.1468-0017.2006.00297.x.

Heckhausen, H., \& Gollwitzer, P. M. (1987). Thought contents and cognitive functioning in motivational versus volitional states of mind. Motivation and Emotion, 11, 101-120. https://doi. org/10.1007/bf00992338.

Heinzelmann, N., Ugazio, G., \& Tobler, P. (2012). Practical implications of empirically studying moral decision-making. Frontiers in Neuroscience, 6, 94. https://doi.org/10.3389/fnins.2012.00094.

Helzer, E. G., Fleeson, W., Furr, R. M., Meindl, P., \& Barranti, M. (2017). Once a utilitarian, consistently a utilitarian? Examining principledness in moral judgment via the robustness of individual differences. Journal of Personality, 85, 505-517. https ://doi.org/10.1111/jopy.12256.

Jenni, K., \& Loewenstein, G. (1997). Explaining the identifiable victim effect. Journal of Risk and Uncertainty, 14, 235-257.

Kuznetsova, A., Brockhoff, P. B., \& Christensen, R. H. B. (2017). lmerTest package: Tests in linear mixed effects models. Journal of Statistical Software. https://doi.org/10.18637/jss.v082.i13.

Lee, J. J., \& Gino, F. (2015). Poker-faced morality: Concealing emotions leads to utilitarian decision making. Organizational Behavior and Human Decision Processes, 126, 49-64. https:// doi.org/10.1016/j.obhdp.2014.10.006.

McDonald, M. M., Defever, A. M., \& Navarrete, C. D. (2017). Killing for the greater good: Action aversion and the emotional inhibition of harm in moral dilemmas. Evolution and Human Behavior, 38, 770-778. https://doi.org/10.1016/j.evolhumbeh av.2017.06.001

Mill, J. S. (1861/2006). Utilitarianism. Stuttgart: Reclam. ISBN: 978-3-15-018461-5
Miller, R. M., Hannikainen, I. A., \& Cushman, F. A. (2014). Bad actions or bad outcomes? Differentiating affective contributions to the moral condemnation of harm. Emotion, 14, 573-387. https ://doi.org/10.1037/a0035361.

Moore, A. B., Clark, B. A., \& Kane, M. J. (2008). Who shalt not kill? Individual differences in working memory capacity, executive control, and moral judgment. Psychological Science, 19, 549-557. https://doi.org/10.1111/j.1467-9280.2008.02122.x.

Moore, A. B., Lee, N. L., Clark, B. A., \& Conway, A. R. (2011). In defense of the personal/impersonal distinction in moral psychology research: Cross-cultural validation of the dual process model of moral judgment. Judgment and Decision Making, 6, 186-195.

Nichols, S., \& Knobe, J. (2007). Moral responsibility and determinism: The cognitive science of folk intuitions. Nous, 41, 663-685. https ://doi.org/10.1111/j.1468-0068.2007.00666.x.

Palan, S., \& Schitter, C. (2018). Prolific. ac-a subject pool for online experiments. Journal of Behavioral and Experimental Finance, 17, 22-27. https://doi.org/10.1016/j.jbef.2017.12.004.

Peirce, J. W. (2007). PsychoPy-Psychophysics software in Python. Journal of Neuroscience Methods, 162, 8-13. https://doi. org/10.1016/j.jneumeth.2006.11.017.

Predebon, J. (2004). Selective attention and asymmetry in the MüllerLyer illusion. Psychonomic Bulletin and Review, 11, 916-920. https://doi.org/10.3758/bf03196721.

Reynolds, C. J., \& Conway, P. (2018). Not just bad actions: Affective concern for bad outcomes contributes to moral condemnation of harm in moral dilemmas. Emotion, 18, 1009. https://doi. org/10.1037/emo0000413.

Rom, S. C., \& Conway, P. (2018). The strategic moral self: Self-presentation shapes moral dilemma judgments. Journal of Experimental Social Psychology, 74, 24-37.

Schaich Borg, J., Hynes, C., Van Horn, J., Grafton, S., \& SinnottArmstrong, W. (2006). Consequences, action, and intention as factors in moral judgments: An fMRI investigation. Journal of Cognitive Neuroscience, 18, 803-817. https://doi.org/10.1162/ jocn.2006.18.5.803.

Shenhav, A., \& Greene, J. D. (2014). Integrative moral judgment: Dissociating the roles of the amygdala and ventromedial prefrontal cortex. Journal of Neuroscience, 34, 4741-4749. https://doi. org/10.1523/jneurosci.3390-13.2014.

Spendel, G. (2006). Luftsicherheitsgesetz und Bundesverfassungsgericht: Eine notwendige Kritik. Recht und Politik, 42, 131-135.

Thomson, J. J. (1985). The trolley problem. The Yale Law Journal, 94, 1395-1415.

Valdesolo, P., \& DeSteno, D. (2006). Manipulations of emotional context shape moral judgment. Psychological Science, 17, 476-477. https://doi.org/10.1111/j.1467-9280.2006.01731.x.

von der Malsburg, T. (2015). saccades: Detection of fixations in eyetracking data. $\mathrm{R}$ package version $0.1-1$. Retrieved from https:// CRAN.R-project.org/package $=$ saccades

Publisher's Note Springer Nature remains neutral with regard to jurisdictional claims in published maps and institutional affiliations. 